\title{
Tetrazole as a Replacement of the Electrophilic Group in Characteristic Prolyl Oligopeptidase Inhibitors
}

\section{Kilpelainen, Tommi P.}

2019-12

Kilpelainen , T P , Tyni , J K, Lahtela-Kakkonen , M K, Eteläinen , T S , Myöhänen , T T \& Wallen , E A A 2019 , ' Tetrazole as a Replacement of the Electrophilic Group in Characteristic Prolyl Oligopeptidase Inhibitors ' , ACS Medicinal Chemistry Letters , vol. 10 , no. 12 , pp. 1635-1640 . https://doi.org/10.1021/acsmedchemlett.9b00394

http://hdl.handle.net/10138/325038

https://doi.org/10.1021/acsmedchemlett.9b00394

unspecified

acceptedVersion

Downloaded from Helda, University of Helsinki institutional repository.

This is an electronic reprint of the original article.

This reprint may differ from the original in pagination and typographic detail.

Please cite the original version. 


\title{
Tetrazole as a Replacement of the Electrophilic Group in Character- istic Prolyl Oligopeptidase Inhibitors
}

\author{
Tommi P. Kilpeläinen ${ }^{\dagger}$, Jonna K. Tyni ${ }^{\ddagger}$, Maija K. Lahtela-Kakkonen ${ }^{\ddagger}$, Tony S. Eteläinen ${ }^{\dagger}$, Timo T. \\ Myöhänen $^{\dagger}$ and Erik A. A. Wallén ${ }^{\perp, *}$
}

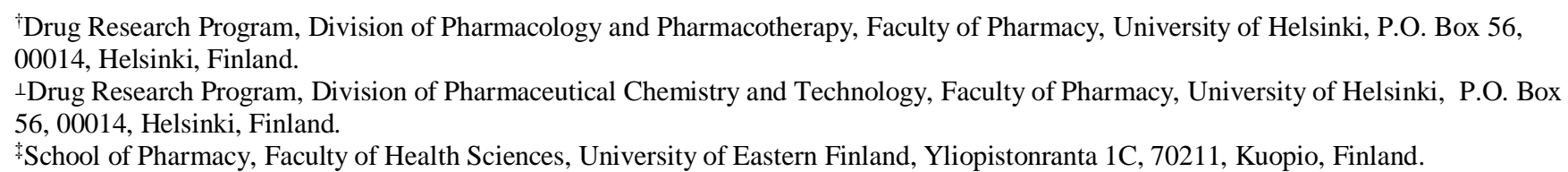

KEYWORDS: Prolyl oligopeptidase, inhibitor, synthesis, tetrazole, alpha-synuclein aggregation, molecular docking

\begin{abstract}
Phenylbutanoyl-aminoacyl-2(S)-tetrazolylpyrrolidines were studied as prolyl oligopeptidase inhibitors. The compounds were more potent than expected from the assumption that the tetrazole would also here be a bioisostere of the carboxylic acid group and the corresponding carboxylic acids are at their best only weak inhibitors. The aminoacyl groups L-prolyl and L-alanyl gave potent inhibitors with $\mathrm{IC}_{50}$ values of 12 and $129 \mathrm{nM}$, respectively. This was in line with typical prolyl oligopeptidase inhibitors, however, we did observe a difference with $N$-methyl-L-alanyl, which gave potent inhibitors in typical prolyl oligopeptidase inhibitors but not in our novel compound series. Furthermore, all studied 4-phenylbutanoyl-aminoacyl-2(S)-tetrazolylpyrrolidines decreased $\alpha$ synuclein dimerization at the concentration of $10 \mu \mathrm{M}$, also when they were only weak inhibitors of the proteolytic activity of the enzyme with an $\mathrm{IC}_{50}$ value of $205 \mu \mathrm{M}$. Molecular docking studies revealed that the compounds are likely to bind differently to the enzyme compared to typical prolyl oligopeptidase inhibitors represented in this study by 4-phenylbutanoyl-aminoacyl-2(S)-cyanopyrrolidines.
\end{abstract}

Prolyl oligopeptidase (PREP) is a serine protease with endopeptidase activity on short proline containing peptides cleaving the peptide on the carboxyl side of the proline residue, and many proline containing peptides, such as oxytocin and several neuropeptides, have been identified as its substrates in vitro (see for review Garcia-Horsman et al. 2007). ${ }^{1}$ PREP is mainly found in the brain, more specifically in caudate nucleus and putamen, hippocampus, and cortex. ${ }^{2}$ However, significant PREP activities and protein levels have been measured also in peripheral tissues such as skeletal muscle, ${ }^{3}$ renal cortex, liver, ovaries, testis, and in ovarian and colorectal tumors. ${ }^{4-6}$ Alterations in the enzyme activity of PREP have been observed in several diseases, including Parkinson's disease, Alzheimer's disease, Lewy body dementia, ${ }^{7}$ and in several types of tumors. ${ }^{8,9}$ Apart from its proteolytic activity, PREP has also other biologically important functions mediated by protein-protein interactions. ${ }^{10,11}$ PREP is able to enhance dimerization of $\alpha$-synuclein $(\alpha \operatorname{Syn})$, the key player in cellular toxicity in Parkinson's disease, via a direct protein-protein interaction. ${ }^{12}$ PREP has highly flexible regions that are in equilibrium between many conformations and inhibitor binding stabilizes these flexible regions into one conformation. ${ }^{13}$ Inhibited PREP has been shown to increase autophagy which is known to enhance clearance of aggregated forms of proteins and decrease dimerization of $\alpha \mathrm{Syn}$ in vitro and in vivo. ${ }^{14,15}$

Almost all known highly potent PREP inhibitors are structurally related to or recognizable mimetics of the peptide substrates with distinct $\mathrm{P} 1, \mathrm{P} 2$ and $\mathrm{P} 3$ sites. ${ }^{16}$ The $\mathrm{P} 1$ moiety is mimicking the important L-proline (Pro) residue in the substrate and it is typically a pyrrolidine with or without an electrophilic group in its 2-position. However, also five-membered heteroaryls such as 2-thienyl and 2-furanyl in the P1-position have resulted in potent inhibitors. ${ }^{17}$ The $\mathrm{P} 2$ moiety can be a wide variety of aminoacyl groups or aminoacyl mimetics with Pro being the most preferred natural aminoacyl group, and the P3 moiety is typically a lipophilic acyl group. There are many examples of variations among the published inhibitors ${ }^{16}$, however, the two carbonyl groups of the connecting amide bonds have been difficult to replace and only few inhibitors lack one or both of them in their structures. ${ }^{18-21}$

The design for the new compounds came from one compound synthesized by the last author of this paper in his earlier research in the search for different replacements for the electrophilic group in PREP inhibitors, where the tetrazolyl group gave a surprisingly potent compound (unpublished data). In the present study, our primary aim was to investigate if 4-phenylbutanoylaminoacyl-2(S)-tetrazolylpyrrolidines as PREP inhibitors had the same structure-activity relationship as typical PREP inhibitor compound series such as 4-phenylbutanoyl-aminoacyl-pyrrolidines and 4-phenylbutanoyl-aminoacyl-2(S)-cyanopyrrolidines. A further aim was to study what effect the novel compound series had on protein-protein-mediated functions of PREP, such as catalysis of $\alpha$ Syn dimerization. We were intrigued by the fact that the tetrazole ring is quite different from typical 2-substituents on the P1 pyrrolidine ring, especially its polar character is exceptional. 


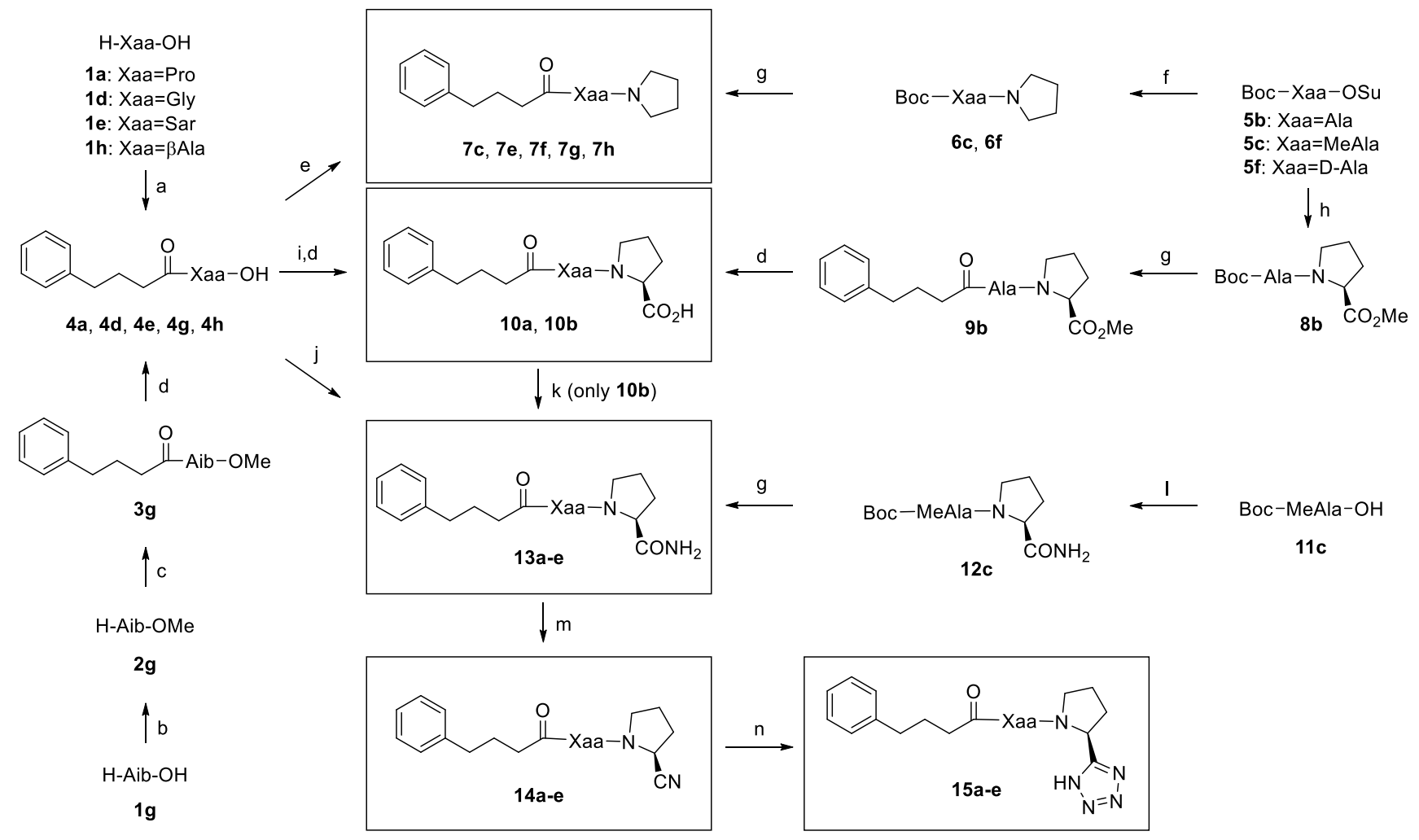

Scheme 1. Synthesis of the compounds, where a specific aminoacyl group is always with the same lower case letter in compound numbering. Reagents and conditions (a) $1.10 \%$ aqueous $\mathrm{Na}_{2} \mathrm{CO}_{3}$, 4-phenylbutanoyl chloride / $\mathrm{Et}_{2} \mathrm{O}$; (b) $\mathrm{SOCl}_{2} / \mathrm{MeOH}$, reflux; (c) 4-phenylbutanoyl chloride, DIPEA / DCM; (d) LiOH / water, $\mathrm{MeOH}$; (e) 1. pivaloyl chloride (or in its place ethyl chloroformate for 4g), $\mathrm{Et}_{3} \mathrm{~N} / \mathrm{DCM}, 0{ }^{\circ} \mathrm{C}$, 2. pyrrolidine, $\mathrm{Et}_{3} \mathrm{~N} / \mathrm{DCM}$; (f) pyrrolidine / DCM; (g) 1. TFA / DCM, $0{ }^{\circ} \mathrm{C}$, 2. 4-phenylbutanoyl chloride, $\mathrm{Et}_{3} \mathrm{~N} / \mathrm{DCM}$ (or alternatively for $6 \mathbf{f}, 2.1 \mathrm{M} \mathrm{NaOH}$, 4-phenylbutanoyl chloride, / $\mathrm{Et}_{2} \mathrm{O}$ ); (h) L-proline methyl ester, DIPEA / DCM; (i) 1. ethyl chloroformate, $\mathrm{Et}_{3} \mathrm{~N} / \mathrm{DCM}, 0{ }^{\circ} \mathrm{C}$, 2. L-proline methyl ester, $\mathrm{Et}_{3} \mathrm{~N} / \mathrm{DCM}$; (j) 1. pivaloyl chloride, $\mathrm{Et}_{3} \mathrm{~N} / \mathrm{DCM}, 0{ }^{\circ} \mathrm{C}, 2$. L-prolinamide, $\mathrm{Et}_{3} \mathrm{~N}$, / DCM; (k) 1. ethyl chloroformate, $\mathrm{Et}_{3} \mathrm{~N} / \mathrm{THF},-10^{\circ} \mathrm{C}, 2 . \mathrm{NH}_{3}(7 \mathrm{M}$ in $\mathrm{MeOH})$; (1) 1. ethyl chloroformate, $\mathrm{Et}_{3} \mathrm{~N}$ / DCM, $0{ }^{\circ} \mathrm{C}$, 2. L-prolinamide, $\mathrm{Et}_{3} \mathrm{~N} / \mathrm{DCM}$; (m) TFAA, $\mathrm{Et}_{3} \mathrm{~N} / \mathrm{THF}$; (n) $\mathrm{NaN}_{3}, \mathrm{NH}_{4} \mathrm{Cl} / \mathrm{DMF}, 100{ }^{\circ} \mathrm{C}$.

There are PREP inhibitors with five-membered heteroaromatics, which look slightly similar to our tetrazoles. ${ }^{22,23}$ However, all of these have an electrophilic carbonyl group in exactly the same position as the typical electrophile. In addition, the tetrazole ring is negatively charged at physiological $\mathrm{pH}$ unlike the five-membered heteroaromatics in the published PREP inhibitors.

The synthetic routes for accessing the compounds in this study are presented in Scheme 1. Compounds 7a (SUAM1221), 7b and 14a (KYP-2047) were obtained from our old compound library at the University of Eastern Finland (14a was also synthesized here only as a synthetic intermediate on the route to 15a but not used in the testing). The connecting amide bonds were synthesized using activation of carboxylic acid groups to corresponding acid chlorides or mixed anhydrides. These activation methods could not be used for non-N-alkylated chiral amino acids due to their susceptibility for racemization, and a milder activation to hydroxysuccinimide esters was used for them. Furthermore, in the case of 2-aminoisobutyric acid (Aib) the low solubility of the amino acid in the solvent of the first step of the synthetic route had to be circumvented, and in the case of $N$-methyl-L-alanine (MeAla) the slightly modified synthetic route gave improved yields and more easily separable intermediates. The 4-phenylbutanoyl-aminoacyl-L-prolinamides were converted to the corresponding nitriles by dehydration with trifluoroacetic anhydride, and then further to the corresponding tetrazoles with sodium azide.

The inhibition of the proteolytic activity of PREP $\left(\mathrm{IC}_{50}\right)$ for the compounds is presented in Table 1. The $\mathrm{IC}_{50}$ values were in the beginning of the project determined using mouse brain homogenate, but we changed later to purified recombinant porcine PREP. Most unsbstituted pyrrolidines and prolinamides were tested with brain homogenate and all nitriles and tetrazoles were tested with purified porcine PREP. The $\mathrm{IC}_{50}$ values for a few compounds were determined with both homogenate and pure enzyme to verify that the values were comparable.

In the beginning of the project earlier uncharted aminoacyl groups, Aib, sarcosine (Sar), MeAla and $\beta$-alanine ( $\beta$ Ala) were evaluated at the P2 site in 4-phenylbutanoyl-aminoacyl-pyrrolidines, which is the most typical PREP inhibitor structure, and compared to the two natural aminoacyl groups Pro and L-alanine (Ala) which have been reported to give the most potent compounds ${ }^{24}$ In this study we did not carry out comparisons to L-phenylalanine, L-methionine, L-leucine, L-valine and glycine (Gly) as they have been previously shown to strongly decrease the inhibitory activity. ${ }^{24}$ 
Table 1. Inhibitory activities of the synthetized compounds.

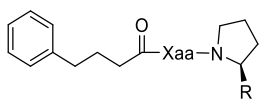

\begin{tabular}{|c|c|c|c|c|c|c|}
\hline Compound & Xaa & $\mathbf{R}$ & $\begin{array}{r}\mathrm{IC}_{50}(\mathrm{nM}) \\
\text { enzyme }\end{array}$ & $\mathrm{IC}_{50} 95 \% \mathrm{Cl}$ & $\begin{array}{r}I_{50}(\mathrm{nM}) \\
\text { homogenate }\end{array}$ & $\mathrm{IC}_{50} 95 \% \mathrm{Cl}$ \\
\hline 7a (SUAM-1221) & Pro & $\mathrm{H}$ & 12 & $10-15$ & - & - \\
\hline $7 b$ & Ala & $\mathrm{H}$ & 147 & 115-191 & - & - \\
\hline $7 c$ & MeAla & $\mathrm{H}$ & - & - & 298 & $142-571$ \\
\hline $7 e$ & Sar & $\mathrm{H}$ & - & - & 5141 & $3950-6604$ \\
\hline $7 f$ & D-Ala & $\mathrm{H}$ & - & - & 35180 & $12600-105300$ \\
\hline $7 g$ & Aib & $\mathrm{H}$ & - & - & 13510 & $8752-22570$ \\
\hline $7 \mathrm{~h}$ & $\beta$ Ala & $\mathrm{H}$ & - & - & 12080 & $7912-17790$ \\
\hline $13 a$ & Pro & $\mathrm{CONH}_{2}$ & 4371 & $3841-4965$ & - & - \\
\hline $13 b$ & Ala & $\mathrm{CONH}_{2}$ & - & - & 6213 & $3325-11340$ \\
\hline $13 c$ & MeAla & $\mathrm{CONH}_{2}$ & - & - & 28800 & $9792-97350$ \\
\hline $13 d$ & Gly & $\mathrm{CONH}_{2}$ & - & - & 153800 & $95170-249800$ \\
\hline $13 e$ & Sar & $\mathrm{CONH}_{2}$ & - & - & 457000 & $329600-637700$ \\
\hline 14a (KYP-2047) & Pro & $\mathrm{CN}$ & 0.86 & $-a$ & 0.3 & -2 \\
\hline $14 b$ & Ala & $\mathrm{CN}$ & 4.06 & $2.0-7.7$ & 3.28 & $2.06-5.22$ \\
\hline $14 \mathrm{c}$ & MeAla & $\mathrm{CN}$ & 5.4 & $4.5-6.4$ & - & - \\
\hline $14 d$ & Gly & $\mathrm{CN}$ & 220 & $117-454$ & 264 & $138-493$ \\
\hline $14 e$ & Sar & $\mathrm{CN}$ & 269 & $-b$ & - & - \\
\hline $15 a$ & Pro & tetrazolyl & 12 & $9.9-14.7$ & - & - \\
\hline $15 b$ & Ala & tetrazolyl & 129 & $71-225$ & 91 & $55-146$ \\
\hline $15 c$ & MeAla & tetrazolyl & 27180 & 22 150-33 410 & - & - \\
\hline $15 d$ & Gly & tetrazolyl & 205400 & $-\mathrm{c}$ & - & - \\
\hline $15 e$ & Sar & tetrazolyl & 10640 & $8110-14390$ & - & - \\
\hline $10 a$ & Pro & $\mathrm{CO}_{2} \mathrm{H}$ & 3626 & 2821-4965 & - & - \\
\hline $10 \mathrm{~b}$ & Ala & $\mathrm{CO}_{2} \mathrm{H}$ & 17540 & $14100-22100$ & - & - \\
\hline
\end{tabular}

Confidence interval could not be determined since $\mathrm{IC}_{50}$ value is lower than lowest used concentration.

Confidence interval could not be determined since Hillslope is greater than -2 .

All explored aminoacyl groups were in fact one methyl/methylene group changes from Ala and of these only MeAla gave a potent compound 7c. The other aminoacyl groups Sar, D-Ala, Aib and $\beta$ Ala gave compounds $\mathbf{7 e}, \mathbf{7 f}, \mathbf{7 g}$ and $\mathbf{7 h}$, respectively, with significantly reduced inhibitory activities.

Pro, Ala, MeAla, Gly and Sar were selected as the aminoacyl groups for our novel tetrazoles. They were synthesized via the corresponding prolinamide and nitrile intermediates, which were also tested for their inhibitory activities. As expected, the prolinamide intermediates 13a-13e had only weak inhibitory activities and the nitrile intermediates $\mathbf{1 4 a - 1 4 e}$ were highly potent inhibitors. The electrophilic nitrile group is known to have favorable interaction with the catalytic Ser554 residue at the active site of the enzyme, and for $\mathbf{1 4 a}$ (which is the well-known reference compound KYP-2047) ${ }^{25}$ this has been described as a reversible covalent interaction. ${ }^{26,27}$ For the nitriles, also Pro, Ala and MeAla gave the most potent inhibitors $14 a, 14 b$ and $14 c$, with $\mathrm{IC}_{50}$ values of $0.86,4.06$ and $5.4 \mathrm{nM}$, respectively. These $\mathrm{IC}_{50}$ values should be used with caution as at least $\mathbf{1 4 a}$ is a covalently binding compound with slow, tight binding enzyme kinetics.

Among our target tetrazoles 15a-15e, Pro and Ala gave the most potent inhibitors $\mathbf{1 5} \mathbf{a}$ and $\mathbf{1 5} \mathbf{b}$, with $\mathrm{IC}_{50}$ values of 12 and

$129 \mathrm{nM}$, respectively. Surprisingly, MeAla gave only a weak inhibitor 15c, which was over 200-fold lower in inhibitory activity than 15b. It is obvious that the N-methyl group on Ala is not favorable in combination with the tetrazole group. Gly and Sar gave the tetrazoles $\mathbf{1 5 d}$ and $\mathbf{1 5 e}$, which had weak inhibitory activities of 205 and $10.6 \mu \mathrm{M}$, respectively. The carboxylic acid analogues 10a and 10b of the most potent tetrazoles 15a and $\mathbf{1 5 b}$, respectively, had only weak inhibitory activities in the micromolar range, indicating no bioisosterism between the tetrazole and the carboxylic acid group in this series of compounds.

For evaluating the ability of the tetrazoles $\mathbf{1 5 a - 1 5 e}$ to reduce $\alpha$ Syn dimerization we used a slightly modified PCA (protein fragment complementation assay) method described in Savolainen et al. 2015. ${ }^{12}$ We used mouse N2A cells in the assay which has high endogenous PREP activity (Suppl. Fig 1.). Results of the assay are shown in Figure 1. Interestingly, all tetrazoles 15a-e decreased $\alpha$ Syn dimerization. The $\alpha$ Syn dimerization assay was performed at the concentration of $10 \mu \mathrm{M}$ and even tetrazole 15d with an $\mathrm{IC}_{50}$ value of $205 \mu \mathrm{M}$ reduced $\alpha \mathrm{Syn}$ dimerization with the same magnitude as tetrazoles $\mathbf{1 5 a}$ and $\mathbf{1 5 b}$ with $\mathrm{IC}_{50}$ values 12 and $129 \mathrm{nM}$, respectively. 


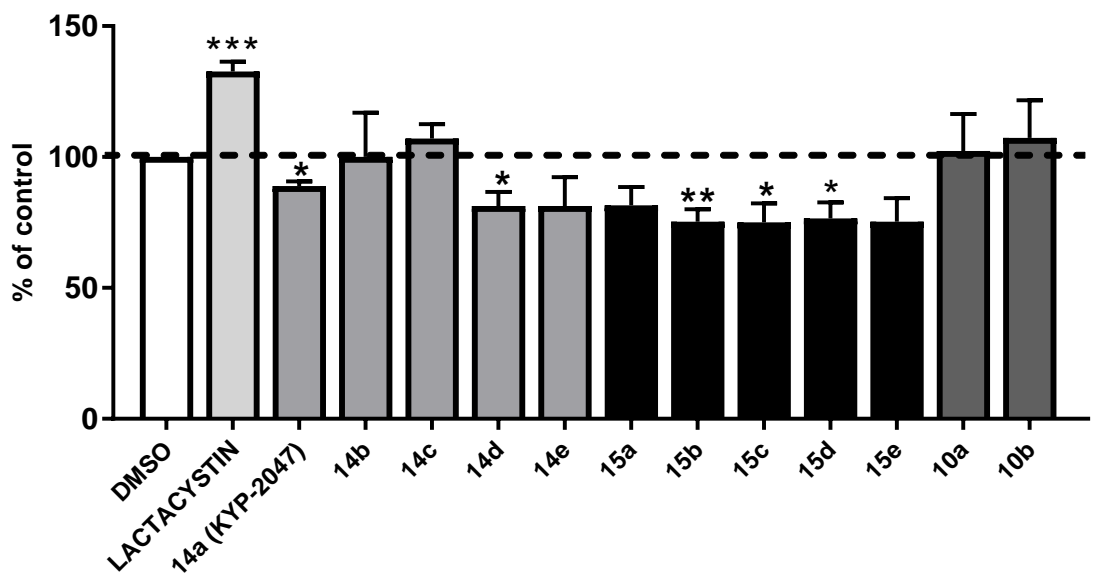

Figure 1. Results of the $\alpha$ Syn- $\alpha$ Syn 2 dimerization in PCA (protein fragment complementation assay) with $4 \mathrm{~h}$ treatment and $10 \mu \mathrm{M}$ concentration. Tetrazoles 15a-e reduced the amount of $\alpha$ Syn dimers $18-25 \%$ compared to control. 14a (KYP-2047), 14d and 14e were the only compounds from nitrile group which were able to reduce $\alpha$ Syn dimerization. Carboxyl acids 10a and 10b were not able to reduce formation of $\alpha$ Syn dimers. Lactacystin serves as positive control for $\alpha$ Syn dimerization. Data are presented as means $+\mathrm{SEM}(\mathrm{n} \geq 3, * * * \mathrm{p}<0.001, * * \mathrm{p}<$ $0.01, * \mathrm{p}<0.05)$

We decided also to examine the nitrile intermediates as a comparison. The nitrile 14a (KYP-2047) had been verified to reduced $\alpha$ Syn dimerization in several earlier studies, but the other nitriles had not been studied. ${ }^{12,14}$ To our surprise, the nitriles 14b and 14c with aminoacyl groups Ala and MeAla did not have an effect on $\alpha$ Syn dimerization although they are 4-5 $\mathrm{nM}$ inhibitors of PREP, and on the other hand, the nitriles 14d and 14e with aminoacyl groups Gly and Sar had an effect although they are only 220-260 $\mathrm{nM}$ inhibitors of PREP. It is important to highlight here that only compounds 14a (89\%, $\mathrm{p}<0.05), 14 d(81 \%, \mathrm{p}<0.05), \mathbf{1 5 b}(75 \%, \mathrm{p}<0.01), \mathbf{1 5 c}(75 \%$, $\mathrm{p}<0.05)$ and 15d $(77 \%, \mathrm{p}<0.05)$ had statistically significant decrease in aSyn dimerization (Student's t-test compared to DMSO control, $\mathrm{n} \geq 3$ ).

The $\alpha$ Syn dimerization assay results for both nitriles and tetrazoles clearly indicate that the structure-activity relationship for affecting this function of PREP is slightly different from inhibiting the proteolytic activity. To study the binding of the nitriles 14a-e and tetrazoles 15a-e to PREP, molecular docking studies were performed (Figure $\mathbf{2 A - F}$ ). The binding pocket included the commonly known S1, S2, and S3 subsites (Figure 2C). Among the nitriles, 14a is known to bind covalently to the catalytically active serine residue (Ser554) at S1. ${ }^{28}$ Other nitriles could be assumed to orient similarly to 14a directing the nitrile group towards S1 and Ser554 (Figure 2D). Indeed, all nitriles could place the nitrile group at $\mathrm{S} 1$ and the phenyl group at S3. The most potent nitriles 14a, 14b, and 14c directed the nitrile group towards Ser554. However, in docking studies 14d and 14e could not orient the nitrile group towards Ser554. This could maybe explain why they are less potent inhibitors than the other nitriles. In the docking protocol the covalent interaction between the nitrile group and Ser554 was not assessed. Thus, the possible covalent bond formation could actually force the nitrile groups to $S 1$.

Interestingly, none of the tetrazoles formed an interaction to Ser554 even though they could place the tetrazole ring at S1. The poses with the tetrazole ring at S1 were compared to the poses of the corresponding nitriles with the nitrile group at S1 (Suppl. Fig. 2-6). The comparison revealed that the tetrazole ring might be positioned in the binding pocket slightly differently than the nitrile group. This can be seen most clearly between compounds 14a and 15a, and compounds $14 \mathbf{d}$ and $\mathbf{1 5 d}$. The two most potent tetrazoles $\mathbf{1 5 a}$ and $\mathbf{1 5} \mathbf{b}$ were inclined to form an interaction between their negatively charged tetrazole group to the positively charged Arg643 instead of Ser554 (Suppl. Fig. 7 and 8). For the other tetrazoles the tetrazole ring at $\mathrm{S} 1$ was not forming any interactions with amino acid residues in the binding pocket (Suppl. Fig. 9-11). Moreover, the pose of 15e was tilted when compared to other tetrazoles or nitriles, and its phenyl group positioned outside the pocket (Suppl. Fig. 11.).

The docking results proposed a putative binding pose in which all the tetrazoles could fit to the binding pocket. In this hypothetical pose the phenyl group was at S1 instead of S3 (Suppl. Fig. 12-16). Tetrazoles might prefer to position the lipophilic benzene ring rather than the hydrophilic tetrazole ring into the hydrophobic S1 pocket. The tetrazole ring does not have a similar ability as the nitrile group to form a covalent bond to Ser554, which is an important interaction for at least some nitriles in anchoring them at S1. As a less hydrophilic moiety, the nitrile group might also be more easily placed into the $S 1$ pocket than the tetrazole ring. Overall, these results suggest that the tetrazoles might have two putative binding poses: the phenyl group at S3 (Figure 2E) or at S1 (Figure 2F).

In conclusion, although the tetrazole group is a known common bioisostere for the carboxylic acid group, the tetrazole is clearly not a bioisostere of a carboxylic acid group in PREP inhibitors. The tetrazoles were more potent inhibitors of the proteolytic activity and $\alpha$ Syn dimerization catalyzing effect of PREP than the corresponding carboxylic acids. The present study further hypothesized that the tetrazoles might have another binding mode in addition to the known binding mode of PREP inhibitors. In this putative binding mode, the tetrazole ring is placed at S3 and the phenyl group at S1. Remarkably, all tetrazoles reduced $\alpha$ Syn dimerization despite the fact that some of them only were weak inhibitors of the proteolytic activity. These findings taken together possibly also indicate that there could be another alternative binding site in enzyme, which affects more the $\alpha$ Syn dimerization catalyzing effect than the proteolytic activity of the enzyme. 


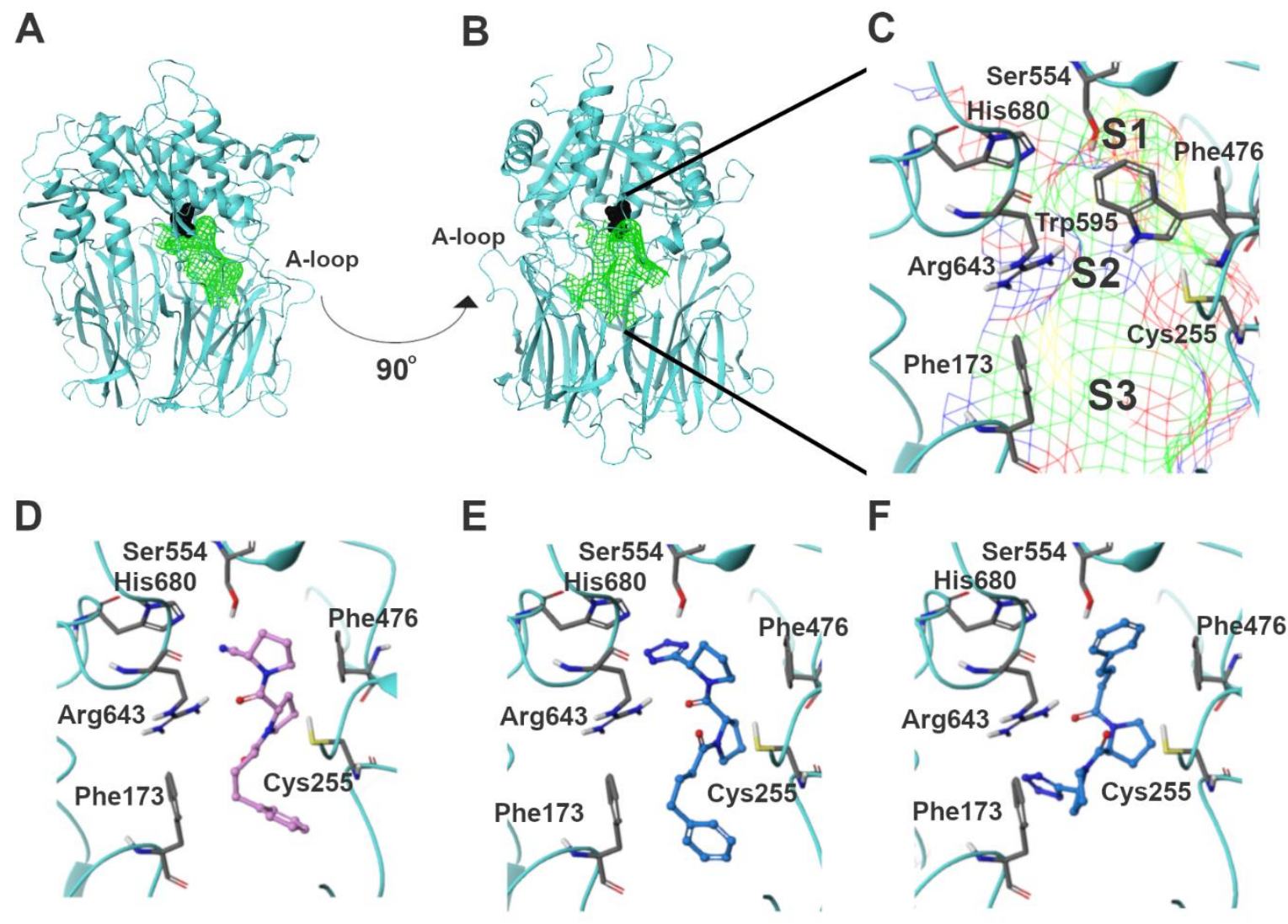

Figure 2. Putative binding site of the tetrazoles with PREP. (A) The crystal structure of PREP. The catalytically active serine residue (Ser554) is marked with black, and the inhibitor-binding site is marked with green mesh. (B) The crystal structure of PREP from site of Figures C-F. (C) The ligand-binding pocket with the S1, S2, and S3 subsites. Green indicates lipophilic, yellow aromatic, red electronegative, and blue electropositive areas. (D) Compound 14a at the inhibitor-binding site. The nitrile points towards Ser554 and forms hydrogen bond to it (not shown in the figure). (E) Compound 15a at the inhibitor-binding site in the commonly known binding mode. (F) A suggested hypothetical binding mode for the tetrazoles with compound 15a as a representative compound.

\section{EXPERIMENTAL SECTION}

Synthesis and characterization of novel compounds. Synthesis and characterization of all compounds are reported in detail in supporting information.

Expression and purification of recombinant porcine PREP. Porcine PREP enzyme was expressed and purified according protocol described by Venäläinen et al. $2002 .{ }^{29}$

Determination of $\mathbf{I C}_{50}$ value. Preparation of mice brain homogenates and detailed procedure for in vitro assay for inhibitory activity are found in supporting information.

PCA for $\alpha$ Syn dimerization. Detailed cell culture, procedure and used DNA constructs are found in supporting information.

Molecular docking studies. Protocol is described in supporting information.

\section{ASSOCIATED CONTENT}

\section{Supporting Information}

The Supporting Information is available free of charge on the ACS Publications website.

\section{AUTHOR INFORMATION}

\section{Corresponding Author}

*Erik A. A. Wallén, orcid.org/0000-0002-2269-5179, E-mail: erik.wallen@helsinki.fi

\section{Author Contributions}

The manuscript was written through contributions of all authors. Chemistry was contributed by TPK and EAAW, pharmacology by TPK, TSE and TTM, and molecular docking studies by JKT and MKLK. All authors have given approval to the final version of the manuscript.

\section{Funding Sources}

This study was supported by grants from Academy of Finland (318327, 305710), HiLIFE (proof-of-concept), Jane and Aatos Erkko Foundation, Business Finland TUTLI funding and Sigrid Juselius Foundation to TTM, and by salary support from Drug Research Doctoral Program at University of Helsinki to TPK and Drug Research Doctoral Program at University of Eastern Finland to JKT. The computational capacity and licenses support provided by CSC-IT Center for Science, Finland, is acknowledged. 


\section{ACKNOWLEDGMENT}

Dr Reinis Svarcbahs is acknowledged for assistance with PREPpurification and Ms Nina Sipari for mass spectrometry. Reference compound 7a (SUAM-1221), 7b and 14a (KYP-2047) were obtained from our old compound library at the University of Eastern Finland (earlier University of Kuopio).

\section{ABBREVIATIONS}

PREP, prolyl oligopeptidase; $\alpha$ Syn, alpha-synuclein; Aib, 2-aminoisobutyric acid; Sar, sarcosine; MeAla, $N$-methyl-L-alanine; $\beta A l a$, beta-alanine; PCA, protein fragment complementation assay.

\section{REFERENCES}

1. García-Horsman, J. A.; Männistö, P. T.; Venäläinen, J. I. On the role of prolyl oligopeptidase in health and disease. Neuropeptides. 2007, 41, 1-24.

2. Myöhänen, T. T.; Venäläinen, J. I.; Tupala, E.; Garcia-Horsman, J. A.; Miettinen, R.; Männistö, P. T. Distribution of immunoreactive prolyl oligopeptidase in human and rat brain. Neurochem. Res. 2007, 32, 1365-1374.

3. Daly, D. J.; Maskrey, P.; Pennington, R. J. T. Characterization of proline endopeptidase from skeletal muscle. Int. J. Biochem. 1985, 17, 521-524.

4. Goossens, F. H.; De Meester, I.; Vanhoof, G.; Scharpé, S. Distribution of prolyl oligopeptidase in human peripheral tissues and body fluids. Eur. J. Clin. Chem. Clin. Biochem. 1996, 34, 17-22.

5. Myöhänen, T. T.; Venäläinen, J. I.; García-Horsman, J. A.; Piltonen, M.; Männistö, P. T. Distribution of prolyl oligopeptidase in the mouse whole-body sections and peripheral tissues. Histochem. Cell Biol. 2008, 130, 993-1003.

6. Myöhänen, T. T.; Pyykkö, E.; Männistö, P. T.; Carpen, O. Distribution of Prolyl Oligopeptidase in Human Peripheral Tissues and in Ovarian and Colorectal Tumors. J. Histochem. Cytochem. 2012, 60, 706-715.

7. Mantle, D.; Falkous, G.; Ishiura, S.; Blanchard, P. J.; Perry, E. K. Comparison of proline endopeptidase activity in brain tissue from normal cases and cases with Alzheimer's disease, Lewy body dementia, Parkinson's disease and Huntington's disease. Clin. Chim. Acta. 1996, $249,129-139$.

8. Liu, J.; Kusinski, M.; Ilic, V.; Bignon, J.; Hajem, N.; Komorowski, J.; Kuzdak, K.; Stepien, H.; Wdzieczak-Bakala, J. Overexpression of the angiogenic tetrapeptide AcSDKP in human malignant tumors. Anticancer Res. 2008, 28, 2813-2817.

9. Larrinaga, G.; Perez, I.; Blanco, L.; López, J. I.; Andrés, L.; Etxezarraga, C.; Santaolalla, F.; Zabala, A.; Varona, A.; Irazusta, J. Increased prolyl endopeptidase activity in human neoplasia. Regul. Pept. 2010, 163, 102-106.

10. Brandt, I.; Gérard, M.; Sergeant, K.; Devreese, B.; Baekelandt, V.; Augustyns, K.; Scharpé, S.; Engelborghs, Y.; Lambeir, A. Prolyl oligopeptidase stimulates the aggregation of a-synuclein. Peptides. 2008, 29, 1472-1478.

11. Di Daniel, E.; Glover, C. P.; Grot, E.; Chan, M. K.; Sanderson, T. H.; White, J. H.; Ellis, C. L.; Gallagher, K. T.; Uney, J.; Thomas, J.; Maycox, P. R.; Mudge, A. W. Prolyl oligopeptidase binds to GAP-43 and functions without its peptidase activity. Mol. Cell. Neurosci. 2009, 41, 373-382.

12. Savolainen, M. H.; Yan, X.; Myöhänen, T. T.; Huttunen, H. J. Prolyl oligopeptidase enhances a-Synuclein dimerization via direct protein-protein interaction. J. Biol. Chem. 2015, 290, 5117-5126.

13. Tsirigotaki, A.; Van Elzen, R.; Van Der Veken, P.; Lambeir, A. ; Economou, A. Dynamics and ligand-induced conformational changes in human prolyl oligopeptidase analyzed by hydrogen/deuterium exchange mass spectrometry. Sci. Rep. 2017, 7.

14. Myöhänen, T. T.; Hannula, M. J.; Van Elzen, R.; Gerard, M.; Van Der Veken, P.; García-Horsman, J. A.; Baekelandt, V.; Männistö, P. T.; Lambeir, A. M. A prolyl oligopeptidase inhibitor, KYP-2047, reduces a-synuclein protein levels and aggregates in cellular and animal models of Parkinson's disease. Br. J. Pharmacol. 2012, 166, $1097-$ 1113.

15. Savolainen, M. H.; Richie, C. T.; Harvey, B. K.; Männistö, P. T.; Maguire-Zeiss, K. A.; Myöhänen, T. T. The beneficial effect of a prolyl oligopeptidase inhibitor, KYP-2047, on alpha-synuclein clearance and autophagy in A30P transgenic mouse. Neurobiol. Dis. 2014, 68, 1-15.

16. Lawandi, J.; Gerber-Lemaire, S.; Juillerat-Jeanneret, L.; Moitessier, N. Inhibitors of prolyl oligopeptidases for the therapy of human diseases: Defining diseases and inhibitors. J. Med. Chem. 2010, 53, 3423-3438.

17. Jarho, E. M.; Venäläinen, J. I.; Poutiainen, S.; Leskinen, H.; Vepsäläinen, J.; Christiaans, J. A. M.; Forsberg, M. M.; Männistö, P. T.; Wallén, E. A. A. 2(S)-(Cycloalk-1-enecarbonyl)-1-(4-phenyl-butanoyl)pyrrolidines and 2(S)-(aroyl)-1-(4-phenylbutanoyl)pyrrolidines as prolyl oligopeptidase inhibitors. Bioorg. Med. Chem. 2007, 15, 2024-2031.

18. Nakajima, T.; Ono, Y.; Kato, A.; Maeda, J.; Ohe, T. Y-29794 a non-peptide prolyl endopeptidase inhibitor that can penetrate into the brain. Neurosci. Lett. 1992, 141, 156-160.

19. Tarrago, T.; Kichik, N.; Segu, J.; Giralt, E. The natural product berberine is a human prolyl oligopeptidase inhibitor. ChemMedChem. 2007, 2, 354-359.

20. Kumar, R.; Bavi, R.; Jo, M. G.; Arulalapperumal, V.; Baek, A.; Rampogu, S.; Kim, M. O.; Lee, K. W. New compounds identified through in silico approaches reduce the a-synuclein expression by inhibiting prolyl oligopeptidase in vitro. Sci. Rep. 2017, 7.

21. Tarragó, T.; Kichik, N.; Claasen, B.; Prades, R.; Teixidó, M.; Giralt, E. Baicalin, a prodrug able to reach the CNS, is a prolyl oligopeptidase inhibitor. Bioorg. Med. Chem. 2008, 16, 7516-7524.

22. Tsutsumi S.; Okonogi T.; Shibahara S.; Ohuchi S.; Hatsushiba E.; Patchett A. A.; Christensen B. G. Synthesis and structure-activity relationships of peptidyl alpha-keto heterocycles as novel inhibitors of prolyl endopeptidase. J. Med. Chem. 1994, 37, 3492-3502

23. Bal G.; Van der Veken P.; Antonov D.; Lambeir A.-M.; Grellier P.; Croft S.L.; Augustyns K.; Haemers A. Prolylisoxazoles: potent inhibitors of prolyloligopeptidase with antitrypanosomal activity. Bioorg. Med. Chem. Lett. 2003, 13, 2875-2878.

24. Saito, M.; Hashimoto, M.; Kawaguchi, N.; Shibata, H.; Fukami, H.; Tanaka, T.; Higuchi, N. Synthesis and inhibitory activity of acylpeptidyl-pyrrolidine derivatives toward post-proline cleaving enzyme; a study of subsite specificity. J. Enzyme Inhib. Med. Chem. 1991, 5, 5175.

25. Jarho, E. M.; Venäläinen, J. I.; Huuskonen, J.; Christiaans, J. A. M.; Garcia-Horsman, J. A.; Forsberg, M. M.; Järvinen, T.; Gynther, J.; Männistö, P. T.; Wallén, E. A. A. A cyclopent-2-enecarbonyl group mimics proline at the $\mathrm{P} 2$ position of prolyl oligopeptidase inhibitors. $J$. Med. Chem. 2004, 47, 5605-5607.

26. Kaszuba, K.; Róg, T.; Danne, R.; Canning, P.; Fülöp, V.; Juhász, T.; Szeltner, Z.; St. Pierre, J. -.; García-Horsman, A.; Männistö, P. T.; Karttunen, M.; Hokkanen, J.; Bunker, A. Molecular dynamics, crystallography and mutagenesis studies on the substrate gating mechanism of prolyl oligopeptidase. Biochimie. 2012, 94, 1398-1411.

27. Van Der Veken, P.; Fülöp, V.; Rea, D.; Gerard, M.; Van Elzen, R.; Joossens, J.; Cheng, J. D.; Baekelandt, V.; De Meester, I.; Lambeir, A.; Augustyns, K. P2-substituted N-acylprolylpyrrolidine inhibitors of prolyl oligopeptidase: Biochemical evaluation, binding mode determination, and assessment in a cellular model of synucleinopathy. J. Med. Chem. 2012, 55, 9856-9867.

28. Venäläinen, J. I.; Garcia-Horsman, J. A.; Forsberg, M. M.; Jalkanen, A.; Wallén, E. A. A.; Jarho, E. M.; Christiaans, J. A. M.; Gynther, J.; Männistö, P. T. Binding kinetics and duration of in vivo action of novel prolyl oligopeptidase inhibitors. Biochem. Pharmacol. 2006, 71, 683-692.

29. Venäläinen, J. I.; Juvonen, R. O.; Forsberg, M. M.; Garcia-Horsman, A.; Poso, A.; Wallen, E. A. A.; Gynther, J.; Männistö, P. T. Substrate-dependent, non-hyperbolic kinetics of pig brain prolyl oligopeptidase and its tight binding inhibition by JTP-4819. Biochem. Pharmacol. 2002, 64, 463-471. 
For Table of Contents Use Only

Tetrazole as a Replacement of the Electrophilic Group in Characteristic Prolyl Oligopeptidase Inhibitors

Tommi P. Kilpeläinen, Jonna K. Tyni, Maija K. Lahtela-Kakkonen, Tony S. Eteläinen, Timo T. Myöhänen and Erik A. A. Wallén

$\begin{array}{llr}\text { Xaa } & I_{50}(\mathrm{nM}) & \begin{array}{c}\text { Effect on } \alpha \text { Syn } \\ \text { dimeriz. at } 10 \mu \mathrm{M}\end{array} \\ \text { Pro } & 12 & 82 \% \\ \text { Ala } & 129 & 75 \% \\ \text { Sar } & 10640 & 75 \% \\ \text { MeAla } & 27180 & 75 \% \\ \text { Gly } & 205400 & 77 \%\end{array}$

